\title{
Initial Experience of Face Augmentation Using Fat Graft-Platlet Rich Plasma Mix
}

\author{
Adel M. Tolba, Mohamed Nasr \\ Plastic Surgery Unit, General Surgery, Zagazig University, Zagazig, Egypt \\ Email: abdelrahmantolba@yahoo.com
}

Received 3 October 2015; accepted 10 November 2015; published 13 November 2015

Copyright (C) 2015 by authors and Scientific Research Publishing Inc.

This work is licensed under the Creative Commons Attribution International License (CC BY). http://creativecommons.org/licenses/by/4.0/

c) (i) Open Access

\begin{abstract}
Plastic surgeons accustomed to use autologous fat grafs for augmentation of soft tissues in the last two decades. The main drawback of fat grafting is unpredictable graft resorption. Several studies have searched for new ways of increasing the viability of the transplanted tissue to overcome this disadvantage. The most recent and promising approach is to mix the fat graft with Platelet-Rich Plasma (PRP) before transplantation. The purpose of this article is to present the initial experience using the autologous fat injection with platlet rich plasma as a method for fascial augmentation.
\end{abstract}

\section{Keywords}

Fat Grafting, Platelet-Rich Plasma (PRP), Experience

\section{Introduction}

Autologous fat grafting enables repair and augmentation of fascial volume loss and is increasingly used in plastic and reconstructive surgery. Autologous fat tissue has been considered to be an ideal filler and became a clinical reality for fascial augmentation as it is biocompatible, versatile, natural-appearing, non immunogenic, inexpensive, and readily obtainable with low donor site morbidity

([1], HYPERLINK “http://www.ncbi.nlm.nih.gov/pmc/articles/PMC3631549/” [2]).

In 1893, fat grafting for the face was reported when Franz Neuber grafted upper arm fat to a patient's cheek [3]. The advent of liposuction popularized the concept of fat grafting by injection [4].

Fat tissue is a rich source of pluripotential cells: preadipocytes, adipocytes, mesenchymal stem cells (MSC), endothelial cells, etc., that can survive, integrate into host tissue and secrete cytokines and growth factors: vascular growth factor (VEGF), hepatocyte gowth factor (HGF) insulin-like growth factor (IGF), platelet derived growth factor (PDGF), and transforming growth factor-beta (TGF $\beta$ ) [5]. 
The unpredictable rate of resorption, which ranges from $25 \%$ - $80 \%$ is the main disadvantage of using autologous fat grafting to correct soft tissue defects [6]. Histological analyses of fat grafts detect acute necrosis as well as oily cysts, calcification, and the formation of connective tissue [7]. To obviate these drawbacks, some strategies have been advanced to improve graft viability. Among these, most recently, autologous platelet-rich plasma (PRP) assisted fat grafting is attracting many surgeons [8].

Platelet-rich plasma (PRP) was initially developed in the 1970s; recent technologic advances have enabled the administration of PRP to move from the hospital setting into outpatient and ambulatory surgical centers...even into physicians' offices [9]. Platelets act through the degranulation of the $\alpha$-granules, which contain the synthesized growth factors (PDGF, TGF $\beta$, IGF, VEFG and endothelial growth factor) that bind to the surface of cell membranes to stimulate haemostasis, normal healing (activates angiogenesis, cell proliferation, cell differentiation and new matrix formation for tissue repair). So, Platelets are considered as natural reservoir of growth factors that could be used to regenerate tissues.

So, autologous PRP adds to the natural healing process being a source of multiple growth factors, safe due to its autologous nature, and is produced simply as needed from the patient's blood [10] [11].

More than 5000 studies documented the benefits and safety of PRP in enhancement of bone regeneration [12], wound healing [13], tendon and cartilage healing [14], corneal healing [15], and skin rejuvenation [16]. PRP is thus used more and more often in the plastic, reconstructive and aesthetic surgery fields [17]-[19].

This paper presents the initial experience using the autologous fat njection with platlet rich plasma as a method for fascial augmentation.

\section{Patients and Methods}

Between 2010 and 2013, 40 patients were treated in plastic surgery unit of Zagazig University Hospitals using the autologous fat injection with platlet rich plasma as a method for fascial augmentation.

All patients underwent the procedure as one day case and were evaluated clinically and photographically before and after operation.

An informed consent about surgery, possible outcome, and complications was obtained.

This study was approved by the IRP of Zagazig University Hospitals.

Procedure:

Under general anaesthesia, Fat harvesting was done from the lower abdomen, lateral or medial thigh with strict attention to sterility and infection control principles and under cover of prophylactic broad spectrum antibiotic.

Through a 2 - 3 mm stab incision, a small cannula was inserted and local anesthetic (lidocaine with 1/200,000 epinephrine) was dispersed in donor site (1cc of local anesthetics for each 1cc of harvested fat), after 10 to 15 minutes fat harvesting was started through the same stab incision.

We used a $10 \mathrm{~mm}$ syringe to induce negative pressure. By withdrawing the plunger (2 - $3 \mathrm{~mm}$ ), negative pressure was provided, back and forth hand movement gathered fat into the syringe through an opening located on the lateral side of a cannula (2 - $3 \mathrm{~mm})$.

Harvested fat was placed on sterile gauze over sterile cup, washed with saline and dried before loading into syringes and then was transferred to 1 cc syringes by a sterile surgical spoon or spatula.

Blood was withdrawn from patient's peripheral vein in Regen-tubes containing sodium citrate anti-coagulant. The whole blood was centrifugated at $3000 \mathrm{rpm}$ for $5 \mathrm{~min}$. As Regen-tubes contain a special gel separator, $99 \%$ of red blood cells were discarded from the plasma at the bottom of the gel. Platelets and white blood cells were pellet on top of the gel and re-suspended in plasma by gently mixing the tube. The cell suspension is called the PRP.

The purified fat was mixed with PRP (20\% of PRP to $80 \%$ of purified fat).

A blunt 18- or 17-gauge cannula with one distal aperture just proximal to the tip and $1 \mathrm{ml}$ syringe were used for transfer of fat-PRP mixture.

The cannula is inserted through the 1 - $2 \mathrm{ml}$ hidden incisions and advanced through the tissues to the appropriate plane. As the cannula was withdrawn, fatty tissue is injected into the pathway of the retreating cannula. No fat was placed during advancement of the cannula to avoid placement of the fat in clumps and to encourage nutrition and integration of the grafted tissue by placement in small aliquots. Placement of fat in tiny aliquots of about one tenth of a milliliter with each pass of the cannula is essential. Dramatic volume corrections were 
possible by making many passes of the tiny aliquots in one procedure.

Postoperative broad spectrum antbiotic and analgesic anti-inflamatory was described for all patients for one week.

Patients were advised to reduce or avoid movements of facial muscles if possible as agressive movements might traumatize the newly formed blood vessels around injected fat grafts Patients were followed up 7 days, 1 , 3, 6, 12 and 24 months postoperatively and photographed during each visit.

Usually after 6 months, second procedure was indicated when the outline of facial contour was not satisfactorily improved to add more volume of fat grafts to the area. In this study, the final results in each patient after operation were evaluated by the patients and the surgeons according to the comparison of pre- or postoperative photos for the degree of improvement. The degree of improvement was evaluated and was classified as excellent, satisfactory, and unsatisfactory.

\section{Results}

10 patients were excluded as they did not complete follow up. Of the 30 patients, 18 were females and 12 were men. The average patient age was 30 years (range, 18 - 55 years).

The indications for fat grafting-PRP were rejuvenation and soft tissue augmentation (10 patients as isolated procedure and 5 patients after face lift), after rhinoplasty (3 patients), traumatic and developmental facial asymmetries (12 patients) (Table 1).

A total of 40 treatments were performed in the 30 patients (average, 1.3 treatments per patient). In this series, the most common injection sites were the cheek and mandibular concave regions. 8 patients underwent a second fat grafting treatment. With an average of 6 months after the first treatment, while 2 patients needed third refilling (Table 2).

Table 1. Indication of fat grafting-PRP mixture injection.

\begin{tabular}{cc}
\hline Indication & Number of patients \\
\hline Rejuvenation and soft & $15(50 \%)$ \\
Tissue augmentation & \\
Isolated procedure & $10(33 \%)$ \\
After facelift & $5(17 \%)$ \\
After rhinoplasty & $3(10 \%)$ \\
Traumatic fascial & $10(33 \%)$ \\
asymmetry & \\
Developmental fascial & $2(6.6 \%)$ \\
Assymetry & \\
\hline
\end{tabular}

\section{Table 2. Injection position and the number of cases.}

\begin{tabular}{cc}
\hline Position & Number of patients \\
\hline Cheek concave & $20(66 \%)$ \\
Mandibular concave & $18(60 \%)$ \\
Zygomatic area & $10(33 \%)$ \\
Frontal area & $2(6.6 \%)$ \\
Temporal area & $4(13.2 \%)$ \\
Perioral area & $6(20 \%)$ \\
Perioricular volume loss & $1(3.3 \%)$ \\
Chin & $4(13.2 \%)$ \\
Nose & $3(10 \%)$ \\
\hline
\end{tabular}


Refilling was performed in case of suboptimal outcome at the patient's request or upon physician suggestion. The follow-up after the last fat injection of a patient was 2 years. All patients received an autologous fat injection between 1 and 3 times into 1 to 3 areas of their faces. The volume of each injection was ranging from 2 to $50 \mathrm{ml}$ (Table 3).

There were no indurations, cysts, infections or visible scar in this series, or any serious complications such as fat emboli due to intravascular injection.

Bruising of the treated area occurred in $50 \%$ of patients $(n=15)$, and redness with some swelling occurred in $10 \%$ of patients $(n=3)$, all of which resolved within an average of 4 days after the procedure. No surface irregularities, such as lumpiness or unevenness, were observed among our patients.

The final results evaluated by the patients and the plastic surgeons revealed that $70 \%$ of the patients in this series were assessed as excellent. $20 \%$ of the patients were satisfactory. $10 \%$ of the patients were unsatisfactory (Figures 1-3).

Table 3. Volume of fat-PRP mixture.

\begin{tabular}{ccc}
\hline Injection site & Filling volume & Average vol. \\
Cheek & $15-40$ & 25 \\
Madibular area & $10-20$ & 12 \\
Zygomatic area & $4-9$ & 7 \\
Perioral region & $3-6$ & 4 \\
Temporal area & $6-12$ & 9 \\
Perioricular area & $1-2$ & 1.5 \\
Frontal area & $4-8$ & 6 \\
Nose & $2-4$ & 3 \\
\hline
\end{tabular}

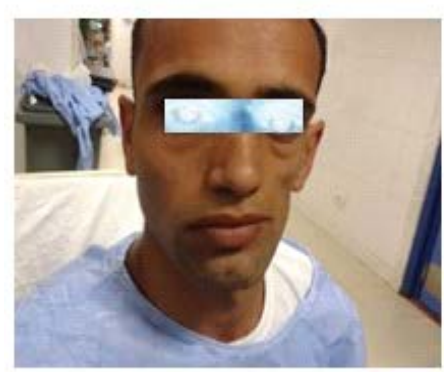

(a)

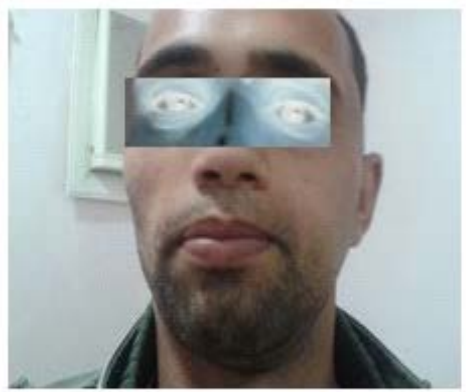

(d)

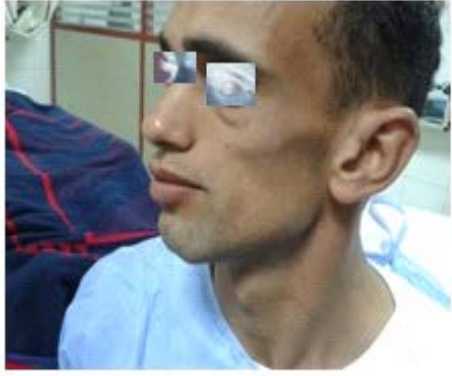

(b)

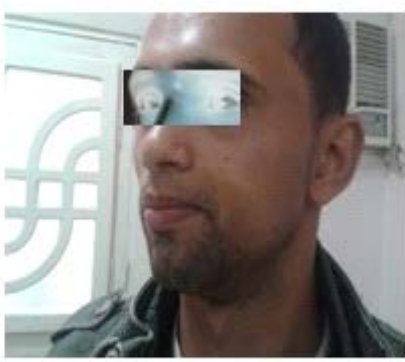

(e)

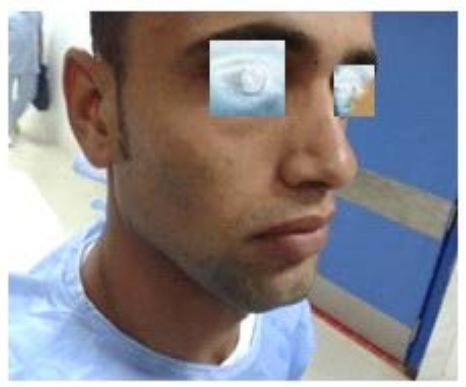

(c)

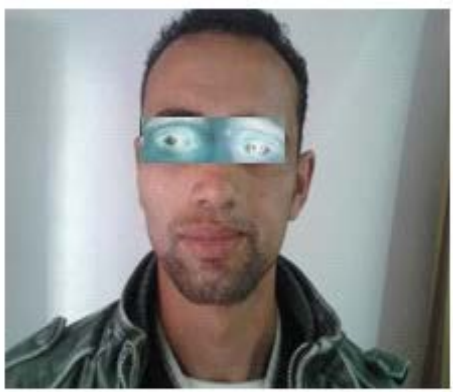

(f)

Figure 1. (a)-(c) Preoperative; (d)-(f) postoperative. 


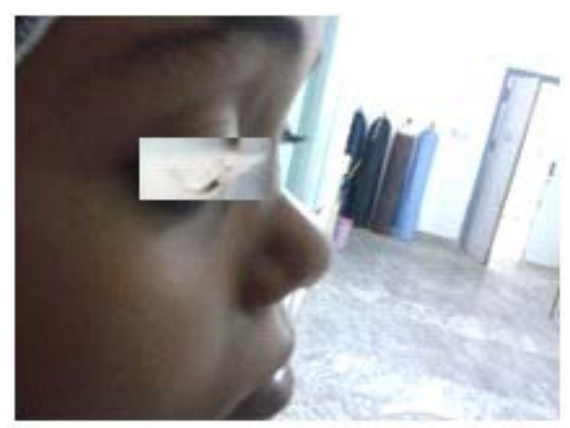

(a)

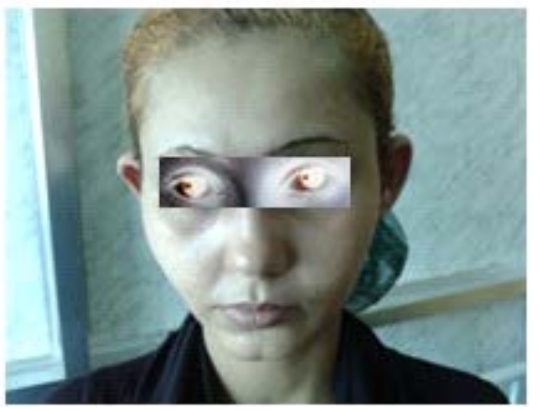

(c)

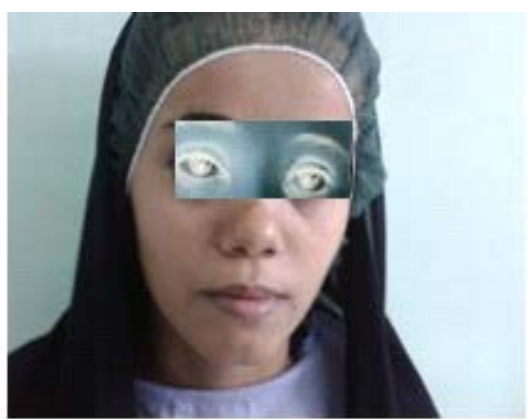

(b)

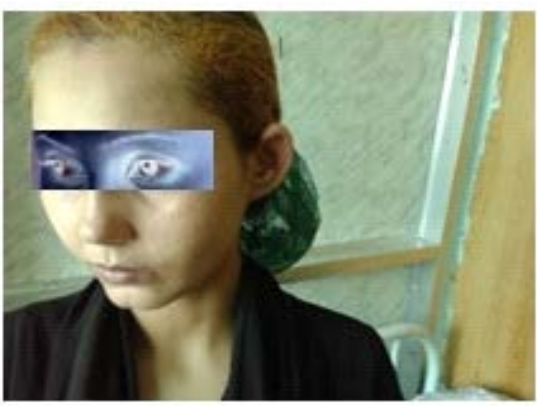

(d)

Figure 2. (a) (b) Preoperative; (c) (d) postoperative.

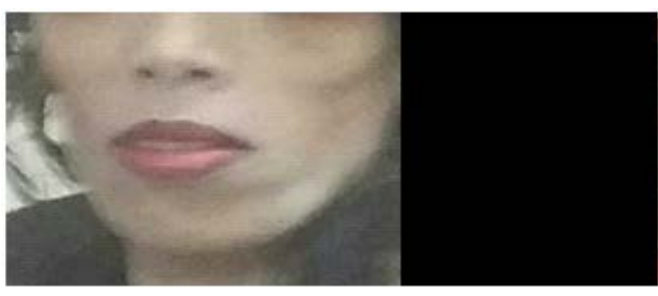

(a)

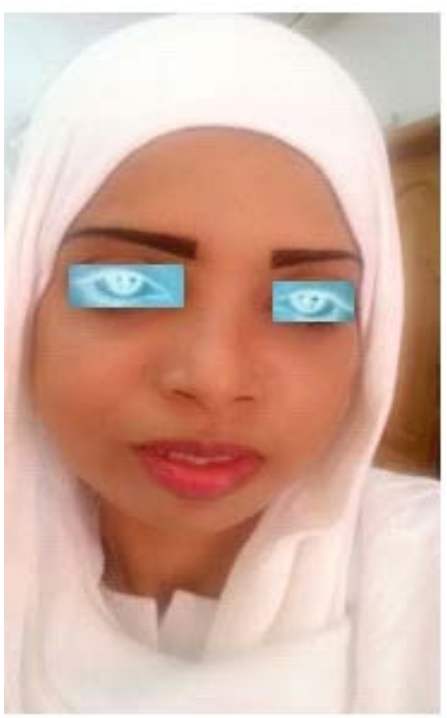

(c)

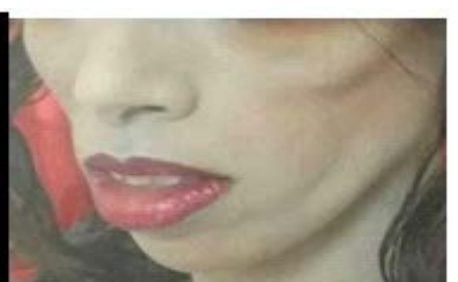

(b)

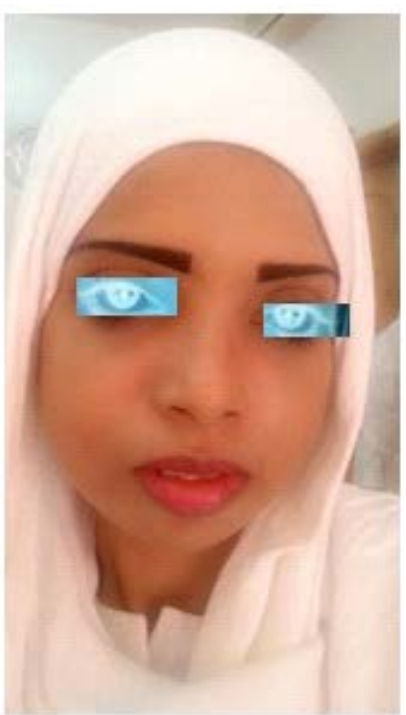

(d)

Figure 3. (a) (b) Preoperative; (c) (d) postoperative. 


\section{Discussion}

Lipofilling is known since the beginning of 20th century. Its first indications were for aesthetic surgery of the face [20], then for hands [21]. It is also useful for tissue loss due to an accident, operation, congenital disease or lipodystrophy [22] [23]. This technique is thus also recommended for wound healing, [24] scar reduction, [25] [26] radio-dermatitis treatment and correction of acne scars [27]. In 1986, Coleman described the method for the fat harvesting, purification and infiltration [28] [29] which takes into account the fragility of fat cells, the survival rate and longstanding results depend partially on indications and patients but mostly on surgical technique. However, the fat grafting survival is unpredictable, with a variable resorption rate reported throughout the literature. Many techniques have been proposed to improve the survival rate of fat grafting and its predictability. The most efficient technique proposed until today is to highly enrich the grafted tissue on mesenchymal stem cells. But, it is time consuming, expensive with significant harvested fat loss, and the results still remain unpredictable. Stimulation of the transplanted tissue by growth factors is another approach, However, the exogenous and synthetic growth factors treatment didn't give the desired expected results in clinic (e.g., wound healing treatment, bioengineering). Recently, autologous platelets considered as a natural reservoir of growth factors has been used for different pathologies [5]. So, we suggest that its addition to fat grafts could be a solution to boost stem cell survival, multiplication and differentiation to finally improve the long standing results of lipofilling efficiently and simply.

Platelet-rich plasma is a concentration of autologous human platelets (three to five times higher than baseline platelet count) in a small volume of plasma. It contains the main growth factors that are released by degranulation of platelets to start the wound-healing process. Platelet-rich plasma stimulates angiogenesis processes and proliferation of adipose-derived stem cells. Eppley et al. reported that platelet-rich plasma growth factors stimulate endothelial cells near their application, favoring proliferation and formation of new capillaries [30]. Also, PRP enhances fat graft survival via proliferation of adipose stromal cells (ASCs) or stimulation of ASCs to differentiate into adipocytes [31]. In addition, Kakudo et al. showed that activated platelet-rich plasma contains large amounts of PDGF-AB and TGF- $\beta 1$ that promote the proliferation of human adipose-derived stem cells and human dermal fibroblast in vitro [32]. Lastly, Bendinelli et al. reported the anti-inflammatory effect of PRP by a reduction of COX2 and CXCR4 gene expression [33].

Successful clinical applications have been reported using platelet-rich plasma, such as periodontal [34] and oral surgery [35], cosmetic surgery [36], spinal fusion [37], cardiac bypass surgery [38], and treatment of soft tissue ulcers [39].

Based on these literatures, we hypothesized that adding PRP to fat preparation may be a reliable way to bring appropriate nutrient at the early moments of transplantation to improve fat survival and render the result more predictable.

Careful assessment of patients during initial consultation specially volume loss with its various patterns (diffuse or localized) and its cause; skin texture and thickness are important before treatment and as fat graft resorption is the main drawback [40] [41] because adipocytes have short lifespans once removed from the body, and they do not react well to excessive handling, refrigeration or major trauma during tissue collection or processing and could be dramatically reduced by using good technique. Coleman et al., recommends a small quantity of fat injection in fine layers [28] to increase the proportion of fat graft surface area to recepient bed. The total procedure could be done under local or general anaesthesia, according to patient/physician preference and the amount of fat volume previewed to be grafted...

The donor site in our series is the abdomen and thigh, but the fat could be harvested from any location that presents patient-specific, and dependent on patient/physician preference. There is no compelling evidence regarding harvest site and efficacy of fat grafting [42].

As adipocyte viability decreases with increasing negative suction pressure [43], mechanical liposuction by machine should be avoided ( $500 \mathrm{ml} \mathrm{Hg}$ ), and only manual harvesting offers a satisfied fat graft quality [44]. We used low pressure vacuum, created by a 2 cc withdrawing plunger of a $10 \mathrm{ml}$ syringe connected to a blunt cannula with a single distal opening $2-3 \mathrm{ml}$ in diameter that combines efficient collection of fat parcels with minimal neurovascular damage.

Various methods for separating out blood, infiltration fluid, and cell debris from healthy adipocytes with minimal trauma have been described, none has been determined to be superior to the others, but it is accepted that techniques involving less manipulation gives better outcomes [45] [46]. We washed the aspirated fat is with $0.9 \%$ 
normal saline, and then filtred the harvested fat by sterile gauze over sterile cup.

In spite of the presence of different techniques for PRP preparation in the market, we prefered Regen Lab to prepare autologous PRP from whole patient blood. As it is a simple, safe, maintains low cost with no specialized skill and offers the best platelet concentration and survival, with highest growth factor secretion [47]-[49].

We add $20 \%$ of PRP to $80 \%$ of purified fat in all cases through a 3-ways connector, while Modarrassi, [5] adds different amounts of PRP depending on the indication and the localization of the receiver site. For skin rejuvenation, superficial scars correction and under eye site ( $>50 \%$ of PRP). For deep filler indication (nasolabial folds, lips, or soft tissue defect) He added $20 \%$ of PRP to $80 \%$ of purified fat.

We used small syringe $(1 \mathrm{ml})$ connected to special blunt cannula $(0.75 \mathrm{~mm}$ to $1.65 \mathrm{~mm})$ for precise fat placement. And as suggested by Coleman, fat is injected in small parcels and thin strips in several layers. Before injection, it is recommended to create some tunnels, especially in nasolabial region or in scars, to release fibrotic tissues. The fat graft is then placed by a withdrawing way [28].

Possible problems that may occur with fat grafting include palpable nodules, firmness, fat necrosis, and fat cysts [50]. None of these complications were observed in our patient population, probably because the use of fatPRP mix [51]-[53] and only small amounts of small-diameter fat particles were used, and these were injected into well-vascularized tissue. Bruising was the most common adverse effect ( $50 \%$ of patients) that resolved after approximately 4 days.

Inspite of standardization of technique for all patients, there was a variation in the degree of volume retention between patients in this study. Volume retention was also variable between regions in same individual patient, this intra-patient variability may be explained by differences in blood supply or positioning postoperatively (laying on 1 side at night). This variation in augmentation is consistent with previous reports in the literature [54]-[57].

Most patients (90\%) were overwhelmingly satisfied, and 10 patients (30\%) required a touch-up procedure. The indication for touch-up procedures in all 10 patients who underwent a secondary and tertiary surgery was correction of inadequate volume augmentation from the initial procedure which was not a noticeable asymmetries. The volume of fat_PRP mix injected in secondary and tertiary procedures was usually much less than that used at the original procedure. Touch-up procedures were usually performed with local anesthesia and had less associated downtime after 6 months to allow for initial swelling and resorption to subside. and this is consistent with Gentile [58] who compared PRP assisted lipotransfer with lipotransfer only in breast augmentation. In this study, the patients treated with PRP $(n=50)$ added to the autologous fat grafts showed a $69 \%$ maintenance of the contour after 1 year, whereas the patients of the control group treated with centrifuged fat grafting $(n=50)$ showed a 39\% maintenance. While Salgarello's study [59] revealed that fat-PRP $(n=17)$ is not superior to fat grafting alone $(n=25)$ by the rate of liponecrosis at breast ultrasound.

A limitation of this study is that the results are not quantifiable; they are based only on our own clinical experience.

However, we are currently preparing larger prospective studies that compare fat graft versus fat graft-PRP mix for fascial augmentation.

\section{Conclusions}

Fascial fat graft is biocompatible, inexpensive, readily available, non migratrory with long term results. However, even with the best technique, the survival rate is still quite variable and unpredictable. The addition of PRP to fat grafts represents many advantages with a simple, cost-effective and safe method.

In spite of many studies proved the positive effect of PRP on fat tissues in vitro and animal models, clinical applications are lacking the support of designed randomised controlled trials and further controlled clinical trials to elucidate the effects of PRP on fat graft are still needed. The trials are also needed to optimize the percentage of PRP to fat graft.

\section{References}

[1] Burgess, C.M. (2006) Principles of Soft Tissue Augmentation for the Aging Face. Clinical Interventions in Aging, 1, 349-355. http://dx.doi.org/10.2147/ciia.2006.1.4.349

[2] Bucky, L.P. and Kanchwala, S.K. (2007) The Role of Autologous Fat and Alternative Fillers in the Aging Face. Plastic and Reconstructive Surgery, 120, 89S-97S. http://dx.doi.org/10.1097/01.prs.0000248866.57638.40 
[3] Neuber, G. (1893) Über die Wiederanheilung vollständig vom Körper getrennter, die ganze Fettschicht enthaltender Hautstücke. Zbl F Chirurgie, 30, 16.

[4] Illouz, Y.G. (1986) The Fat Cell "Graft”: A New Technique to Fill Depressions. Plastic and Reconstructive Surgery, 78, 122-123. http://dx.doi.org/10.1097/00006534-198607000-00028

[5] Modarressi, A.S. (2013) Improvement of Fat Grafting with Platelet Rich Plasma: A Simple, Cost-Effective and Safe Method. Medical Grapevine, The Knowledge Bridge between GPS and Specialists.

[6] Missana, M.C., Laurent, I., Barreau, L. and Balleyguier, C. (2007) Autologous Fat Transfer in Reconstructive Breast Surgery: Indications, Technique and Results. European Journal of Surgical Oncology, 33, 685-690. http://dx.doi.org/10.1016/j.ejso.2006.12.002

[7] Coleman, S.R. and Saboeiro, A.P. (2007) Fat Grafting to the Breast Revisited: Safety and Efficacy. Plastic and Reconstructive Surgery, 119, 775-785, 786-787.

[8] Rong, J., Zhang, L. and Zhang, Y.G. (2013) Does Platelet-Rich Plasma Enhance the Survival of Grafted Fat? An Update Review. International Journal of Clinical and Experimental Medicine, 6, 252-258.

[9] Barbara, D.B., Zvi, S., Thomas, E. and George, M. (2007) Clinical Use of Platelet-Rich Plasma in Orthopaedics. American Academy of Orthopaedic Surgeons, 9.

[10] Shoshani, O., Livne, E., Armoni, M., Shupak, A., Berger, J., Ramon, Y., Fodor, L., Gilhar, A., Peled, I.J. and Ullmann, Y. (2005) The Effect of Interleukin-8 on the Viability of Injected Adipose Tissue in Nude Mice. Plastic and Reconstructive Surgery, 115, 853-859. http://dx.doi.org/10.1097/01.PRS.0000153036.71928.30

[11] Man, D., Plosker, H. and Winland-Brown, J.E. (2001) The Use of Autologous Platelet-Rich Plasma (Platelet Gel) and Autologous Platelet-Poor Plasma (Fibrin Glue) in Cosmetic Surgery. Plastic and Reconstructive Surgery, 107, 229-237; Discussion 238-239. http://dx.doi.org/10.1097/00006534-200101000-00037

[12] Marx, R.E., Carlson, E.R., Eichstaedt, R.M., et al. (1998) Platelet-Rich Plasma: Growth Factor Enhancement for Bone Grafts. Oral Surgery, Oral Medicine, Oral Pathology, Oral Radiology, and Endodontology, 85, 638-646. http://dx.doi.org/10.1016/S1079-2104(98)90029-4

[13] Villela, D.L. and Santos, V.L. (2010) Evidence on the Use of Platelet-Rich Plasma for Diabetic Ulcer: A Systematic Review. Growth Factors, 28, 111-116. http://dx.doi.org/10.3109/08977190903468185

[14] Peerbooms, J.C., Sluimer, J., Bruijn, D.J. and Gosens, T. (2010) Positive Effect of an Autologous Platelet Concentrate in Lateral Epicondylitis in a Double-Blind Randomized Controlled Trial: Platelet-Rich Plasma versus Corticosteroid Injection with a 1-Year Follow-Up. American Journal of Sports Medicine, 38, 255-262. http://dx.doi.org/10.1177/0363546509355445

[15] Tanidir, S.T., Yuksel, N., Altintas, O., et al. (2010) The Effect of Subconjunctival Platelet-Rich Plasma on Corneal Epithelial Wound Healing. Cornea, 29, 664-669.

[16] Ebisawa, K., Kagami, H., Kato, R., et al. (2009) Regenerative Medicine for Anti-Aging. Nippon Rinsho, 67, 14021406.

[17] Cervelli, V., Gentile, P., Scioli, M.G., Grimaldi, M., et al. (2009) Application of Platelet-Rich Plasma in Plastic Surgery: Clinical and in Vitro Evaluation. Tissue Engineering Part C: Methods, 15, 625-634. http://dx.doi.org/10.1089/ten.tec.2008.0518

[18] Adler, S.C. and Kent, K.J. (2002) Enhancing Wound Healing with Growth Factors. Facial Plastic Surgery Clinics of North America, 10, 129-146. http://dx.doi.org/10.1016/S1064-7406(02)00005-6

[19] Lacci, K.M. and Dardik, A. (2010) Platelet-Rich Plasma: Support for Its Use in Wound Healing. Yale Journal of Biology and Medicine, 83, 1-9.

[20] Coleman, S.R. (1997) Facial Recontouring with Lipostructure. Clinics in Plastic Surgery, 24, 347-367.

[21] Coleman, S.R. (2002) Hand Rejuvenation with Structural Fat Grafting. Plastic and Reconstructive Surgery, 110, 17311744; Discussion 1745-1747. http://dx.doi.org/10.1097/00006534-200212000-00017

[22] Cohen, G. and Treherne, A. (2009) Treatment of Facial Lipoatrophy via Autologous Fat Transfer. Journal of Drugs in Dermatology, 8, 486-489.

[23] Serra-Renom, J.M. and Fontdevila, J. (2004) Treatment of Facial Fat Atrophy Related to Treatment with Protease Inhibitors by Autologous Fat Injection in Patients with Human Immunodeficiency Virus Infection. Plastic and Reconstructive Surgery, 114, 551-555; Discussion 556-557. http://dx.doi.org/10.1097/01.PRS.0000128427.54445.63

[24] Cervelli, V., Gentile, P. and Grimaldi, M. (2009) Regenerative Surgery: Use of Fat Grafting Combined with PlateletRich Plasma for Chronic Lower-Extremity Ulcers. Aesthetic Plastic Surgery, 33, 340-345. http://dx.doi.org/10.1007/s00266-008-9302-z

[25] Klinger, M., Marazzi, M., Vigo, D. and Torre, M. (2008) Fat Injection for Cases of Severe Burn Outcomes: A New 
Perspective of Scar Remodeling and Reduction. Aesthetic Plastic Surgery, 32, 465-469. http://dx.doi.org/10.1007/s00266-008-9122-1

[26] de Benito, J., Fernandez, I. and Nanda, V. (1999) Treatment of Depressed Scars with a Dissecting Cannula and an Autologous Fat Graft. Aesthetic Plastic Surgery, 23, 367-370. http://dx.doi.org/10.1007/s002669900301

[27] Lam, S.M., Glasgold, R.A. and Glasgold, M.J. (2008) Limitations, Complications, and Long-Term Sequelae of Fat Transfer. Facial Plastic Surgery Clinics of North America, 16, 391-399. http://dx.doi.org/10.1016/j.fsc.2008.05.007

[28] Coleman III, W.P. (1991) Autologous Fat Transplantation. Plastic and Reconstructive Surgery, 88, 736. http://dx.doi.org/10.1097/00006534-199110000-00038

[29] Kaufman, M.R., Bradley, J.P., Dickinson, B., et al. (2007) Autologous Fat Transfer National Consensus Survey: Trends in Techniques for Harvest, Preparation, and Application, and Perception of Short- and Long-Term Results. Plastic and Reconstructive Surgery, 119, 323-331. http://dx.doi.org/10.1097/01.prs.0000244903.51440.8c

[30] Eppley, B.L., Woodell, J.E. and Higgins, J. (2004) Platelet Quantification and Growth Factor Analysis from PlateletRich Plasma: Implications for Wound Healing. Plastic and Reconstructive Surgery, 114, 1502-1508. http://dx.doi.org/10.1097/01.PRS.0000138251.07040.51

[31] Cervelli, V., Gentile, P., Scioli, M.G., Grimaldi, M., Casciani, C.U., Spagnoli, L.G. and Orlandi, A. (2009) Application of Platelet-Rich Plasma in Plastic Surgery: Clinical and in Vitro Evaluation. Tissue Engineering Part C: Methods, 15, 625-634. http://dx.doi.org/10.1089/ten.tec.2008.0518

[32] Kakudo, N., Minakata, T., Mitsui, T., Kushida, S., Notodihardjo, F.Z. and Kusumoto, K. (2008) Proliferation-Promoting Effect of Platelet-Rich Plasma on Human Adipose-Derived Stem Cells and Human Dermal Fibroblasts. Plastic and Reconstructive Surgery, 122, 1352-1360. http://dx.doi.org/10.1097/PRS.0b013e3181882046

[33] Bendinelli, P., Matteucci, E., Dogliotti, G., Corsi, M.M., Banfi, G., Maroni, P. and Desiderio, M.A. (2010) Molecular Basis of Anti-Inflammatory Action of Platelet-Rich Plasma on Human Chondrocytes: Mechanisms of NF- $\kappa$ B Inhibition via HGF. Journal of Cellular Physiology, 225, 757-766. http://dx.doi.org/10.1002/jcp.22274

[34] Robiony, M., Polini, F., Costa, F. and Politi, M. (2002) Osteogenesis Distraction and Platelet-Rich Plasma for Bone Restoration of the Severely Atrophic Mandible: Preliminary Results. Journal of Oral and Maxillofacial Surgery, 60, 630-635. http://dx.doi.org/10.1053/joms.2002.33107

[35] Marx, R.E., Carlson, E.R., Eichstaedt, R.M., Schimmele, S.R., Strauss, J.E. and Georgeff, K.R. (1998) Plateletrich Plasma: Growth Factor Enhancement for Bone Grafts. Oral Surgery, Oral Medicine, Oral Pathology, Oral Radiology, and Endodontology, 85, 638-646. http://dx.doi.org/10.1016/S1079-2104(98)90029-4

[36] Shiffman, M.A. and Kaminski, M.V. (2001) Fat Transfer to the Face: Technique and New Concepts. Facial Plastic Surgery Clinics of North America, 9, 229-37, viii.

[37] Hee, H.T., Majd, M.E., Holt, R.T. and Myers, L. (2003) Do Autologous Growth Factors Enhance Transforaminal Lumbar Interbody Fusion? European Spine Journal, 12, 400-407. http://dx.doi.org/10.1007/s00586-003-0548-5

[38] Del Rossi, A.J., Cernaianu, A.C., Vertrees, R.A., Wacker, C.J., Fuller, S.J., Cilley, J.J. and Baldino, W.A. (1990) Platelet-Rich Plasma Reduces Postoperative Blood Loss after Cardiopulmonary Bypass. Journal of Thoracic and Cardiovascular Surgery, 100, 281-286.

[39] Margolis, D.J., Kantor, J., Santanna, J., Strom, B.L. and Berlin, J.A. (2001) Effectiveness of Platelet Releasate for the Treatment of Diabetic Neuropathic Foot Ulcers. Diabetes Care, 24, 483-488. http://dx.doi.org/10.2337/diacare.24.3.483

[40] Ersek, R.A. (1991) Transplantation of Purified Autologous Fat: A 3-Year Follow-Up Is Disappointing. Plastic and Reconstructive Surgery, 87, 219-227; Discussion 228. http://dx.doi.org/10.1097/00006534-199102000-00001

[41] Chajchir, A. (1996) Fat Injection: Long-Term Follow-Up. Aesthetic Plastic Surgery, 20, 291-296. http://dx.doi.org/10.1007/BF00228458

[42] Rohrich, R.J., Sorokin, E.S. and Brown, S.A. (2004) In Search of Improved Fat Transfer Viability: A Quantitative Analysis of the Role of Centrifugation and Harvest Site. Plastic and Reconstructive Surgery, 113, 391-395; Discussion 396-397. http://dx.doi.org/10.1097/01.prs.0000097293.56504.00

[43] Adanali, G., Erdogan, B., Turegun, M., et al. (2002) A New, T-Shaped Adaptor for Easy, Quick and Efficient Fat Harvesting during Liposuction. Aesthetic Plastic Surgery, 26, 340-344. http://dx.doi.org/10.1007/s00266-002-2040-8

[44] Witort, E.J., Pattarino, J., Papucci, L., et al. (2007) Autologous Lipofilling: Coenzyme Q10 Can Rescue Adipocytes from Stress-Induced Apoptotic Death. Plastic and Reconstructive Surgery, 119, 1191-1199. http://dx.doi.org/10.1097/01.prs.0000258395.81926.d8

[45] Kuran, I. and Tumerdem, B. (2005) A New Simple Method Used to Prepare Fat for Injection. Aesthetic Plastic Surgery, 29, 18-22; Discussion 23. http://dx.doi.org/10.1007/s00266-004-0059-8

[46] Shiffman, M.A. and Kaminski, M.V. (2001) Fat Transfer to the Face: Technique and New Concepts. Facial Plastic 
Surgery Clinics of North America, 9, 229-237.

[47] Marx, R.E. (2004) Platelet-Rich Plasma: Evidence to Support Its Use. Journal of Oral and Maxillofacial Surgery, 62, 489-496. http://dx.doi.org/10.1016/j.joms.2003.12.003

[48] Mazzucco, L., Balbo, V., Cattana, E., Guaschino, R. and Borzini, P. (2009) Not Every PRP-Gel Is Born Equal. Evaluation of Growth Factor Availability for Tissues through Four PRP-Gel Preparations: Fibrinet, RegenPRP-Kit, Plateltex and One Manual Procedure. Vox Sanguinis, 97, 110-118. http://dx.doi.org/10.1111/j.1423-0410.2009.01188.x

[49] Redaelli, A., Romano, D. and Marciano, A. (2010) Face and Neck Revitalization with Platelet-Rich Plasma (PRP): Clinical Outcome in a Series of 23 Consecutively Treated Patients. Journal of Drugs in Dermatology, 9, 466-472.

[50] Assaf, A.Z., Patrick, L.T. and Alexis, M.V. (2012) Sharp-Needle Intradermal Fat Grafting (SNIF). Aesthetic Surgery Journal, 32, 554-561. http://dx.doi.org/10.1177/1090820X12445082

[51] Har-Shai, Y., Lindenbaum, E.S., Gamliel-Lazarovich, A., Beach, D. and Hirshowitz, B. (1999) An Integrated Approach for Increasing the Survival of Autologous Fat Grafts in the Treatment of Contour Defects. Plastic and Reconstructive Surgery, 104, 945-954. http://dx.doi.org/10.1097/00006534-199909020-00008

[52] Shoshani, O., Livne, E., Armoni, M., Shupak, A., Berger, J., Ramon, Y., Fodor, L., Gilhar, A., Peled, I.J. and Ullmann, Y. (2005) The Effect of Interleukin-8 on the Viability of Injected Adipose Tissue in Nude Mice. Plastic and Reconstructive Surgery, 115, 853-859. http://dx.doi.org/10.1097/01.PRS.0000153036.71928.30

[53] Ozsoy, Z., Kul, Z. and Bilir, A. (2006) The Role of Cannula Diameter in Improved Adipocyte Viability: A Quantitative Analysis. Aesthetic Surgery Journal, 26, 287-289. http://dx.doi.org/10.1016/j.asj.2006.04.003

[54] Ersek, R.A. (1991) Transplantation of Purified Autologous Fat: A Three Year Follow-Up Is Disappointing. Plastic and Reconstructive Surgery, 87, 219-227. http://dx.doi.org/10.1097/00006534-199102000-00001

[55] Fulton, J.E., Suarez, M., Silverton, K., et al. (1998) Small Volume Fat Transfer. Dermatologic Surgery, 24, 857-865. http://dx.doi.org/10.1111/j.1524-4725.1998.tb04263.x

[56] Fournier, P.F. (2000) Fat Grafting: My Technique. Dermatologic Surgery, 26, 1117-1128. http://dx.doi.org/10.1046/j.1524-4725.2000.00272.x

[57] Coleman, S.R. (1995) Long-Term Survival of Fat Transplants: Controlled Demonstrations. Aesthetic Plastic Surgery, 19, 421-425. http://dx.doi.org/10.1007/BF00453875

[58] Gentile, P., Di Pasquali, C., Bocchini, I., Floris, M., Eleonora, T., Fiaschetti, V., Floris, R. and Cervelli, V. (2012) Breast Reconstruction with Autologous Fat Graft Mixed with Platelet-Rich Plasma. Surgical Innovation, Epub Ahead of Print.

[59] Salgarello, M., Visconti, G. and Rusciani, A. (2011) Breast Fat Grafting with Platelet-Rich Plasma: A Comparative Clinical Study and Current State of the Art. Plastic and Reconstructive Surgery, 127, 2176-2185. http://dx.doi.org/10.1097/PRS.0b013e3182139fe7 